\title{
WHEN DESIGN NEVER ENDS - A FUTURE SCENARIO FOR PRODUCT DEVELOPEMENT
}

\author{
Pradel, Patrick; Campbell, Robert Ian; Bibb, Richard \\ Loughborough University
}

\begin{abstract}
One of the foundations of product design is the division between production and design. This division manifests as designers aspiring to create fixed iconic archetypes and production replicates endlessly in thousands or millions. Today innovation and technological change are challenging this idea of product design and manufacturing. The evolution of Rapid Prototyping into Additive Manufacturing (AM), is challenging the notion of mass manufacture and consumer value. As AM advances in capability and capacity, the ability to economically manufacture products in low numbers with high degrees of personalisation poses questions of the accepted product development process. Removing the need for dedicated expensive tooling also eliminates the cyclical timescales and commitment to fixed designs that investment in tooling demands. The ability to alter designs arbitrarily, frequently and responsively means that the traditional design process need not be applied and because of this, design processes and practice might be radically different in the future. In this paper, we explore this possible evolution by drawing parallels with principles and development models found in software development.
\end{abstract}

Keywords: Additive Manufacturing, Design practice, New product development

\author{
Contact: \\ Pradel, Patrick \\ Loughborough University \\ Design School \\ United Kingdom \\ p.pradel@lboro.ac.uk
}

Cite this article: Pradel, P., Campbell, R.I., Bibb, R. (2019) 'When Design Never Ends - A Future Scenario for Product Developement', in Proceedings of the 22nd International Conference on Engineering Design (ICED19), Delft, The Netherlands, 5-8 August 2019. DOI:10.1017/dsi.2019.87 


\section{FROM TRADITIONAL TO DIGITALLY-ENABLED PRODUCT DESIGN}

Prior to the industrial revolution, designing and making were inextricably linked as effectively the same activity (i.e. craft). In its effort to reduce production costs, the industrial revolution created design as an independent activity. Moreover, mass manufacturing processes forced upon designers a fixed definition of the design process. In fact, in traditional product design, the design process has a very well-defined end-point (Ulrich and Eppinger, 2012). When a fully-defined, manufacturable design proposal is delivered to production, the design process end and manufacturing begins. Typically, a new design process then starts again for the next version of the same product or for another new one to replace it (Figure 1).

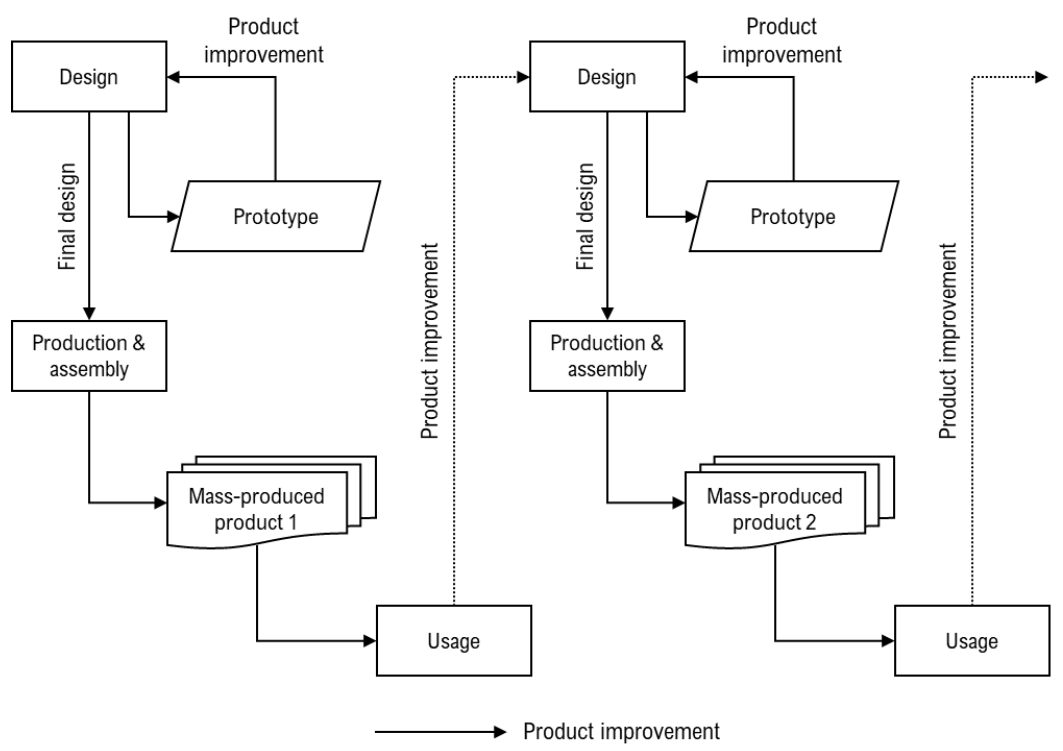

Figure 1. Stepwise development of mass-produced products adapted from (Pahl et al., 2007)

This sequential, linear division between design and manufacture is a consequence of the industrial revolution principle of mass production (Heskett, 2003). In order to reduce the production time and thus reduce product cost, dedicated and often expensive tools are required. When these tools are manufactured, the cost incurred in modifying them can be substantial (Figure 2).

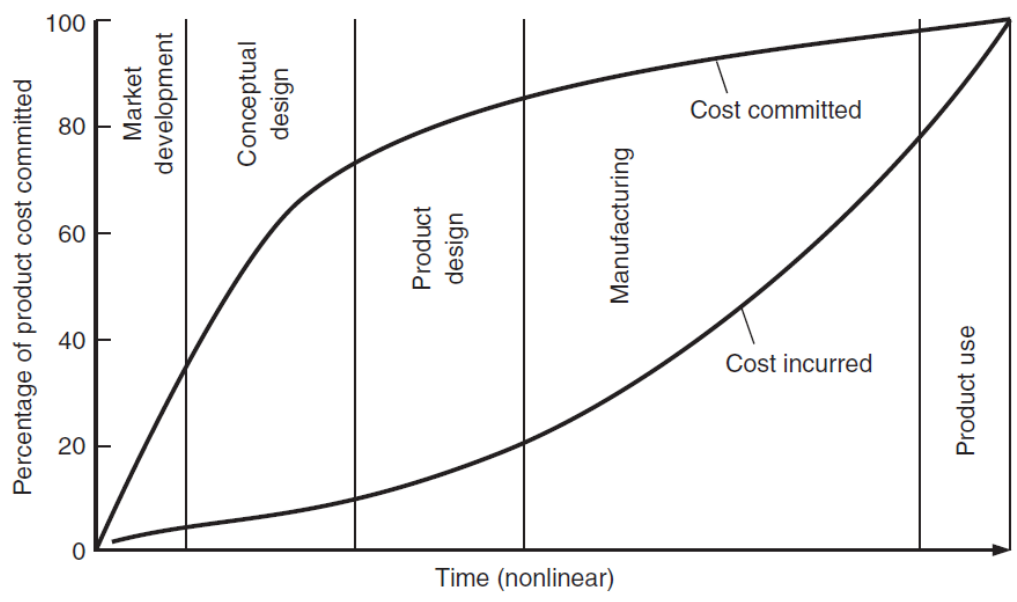

Figure 2. Product cost commitment during phases of the design process from (Dieter and Schmidt, 2012)

Therefore, when the design and manufacture of the tools starts, the design proposal must be "frozen" and the design process finishes (Römer et al., 2001). Since modifications are not possible after this point, before moving into production the design must be fully defined (Eastman, 1980) in other words, the design must (or at least should): 
- Be free of errors,

- Be solved in every aspect,

- Meet all the project requirements (or at least the most important),

- Be completely explicit, so that all information for production is provided.

The development of Rapid Prototyping into Additive Manufacturing (AM also known as 3D Printing) opens up new opportunities for product design (Kumke et al., 2018; Thompson et al., 2016; Pradel et al., 2018). Particularly, removing the need for expensive tooling also removes the imperative to freeze the design; therefore the design proposal could be endlessly modified, updated and upgraded (Campbell et al., 2007). This breaks the traditional division between designing and production and could challenge the accepted model of the product design process and the idea of a "design freeze". However, if a design can be incessantly altered at will, how and when can a design be considered "finished"? How can designs be validated, protected or marketed effectively?

To unravel these questions, this paper proposes a series of principles, taken from software development that may influence the evolution of the product design process and design practice in the future.

\section{DIGITALLY-ENABLED PRODUCT DESIGN PRINCIPLES}

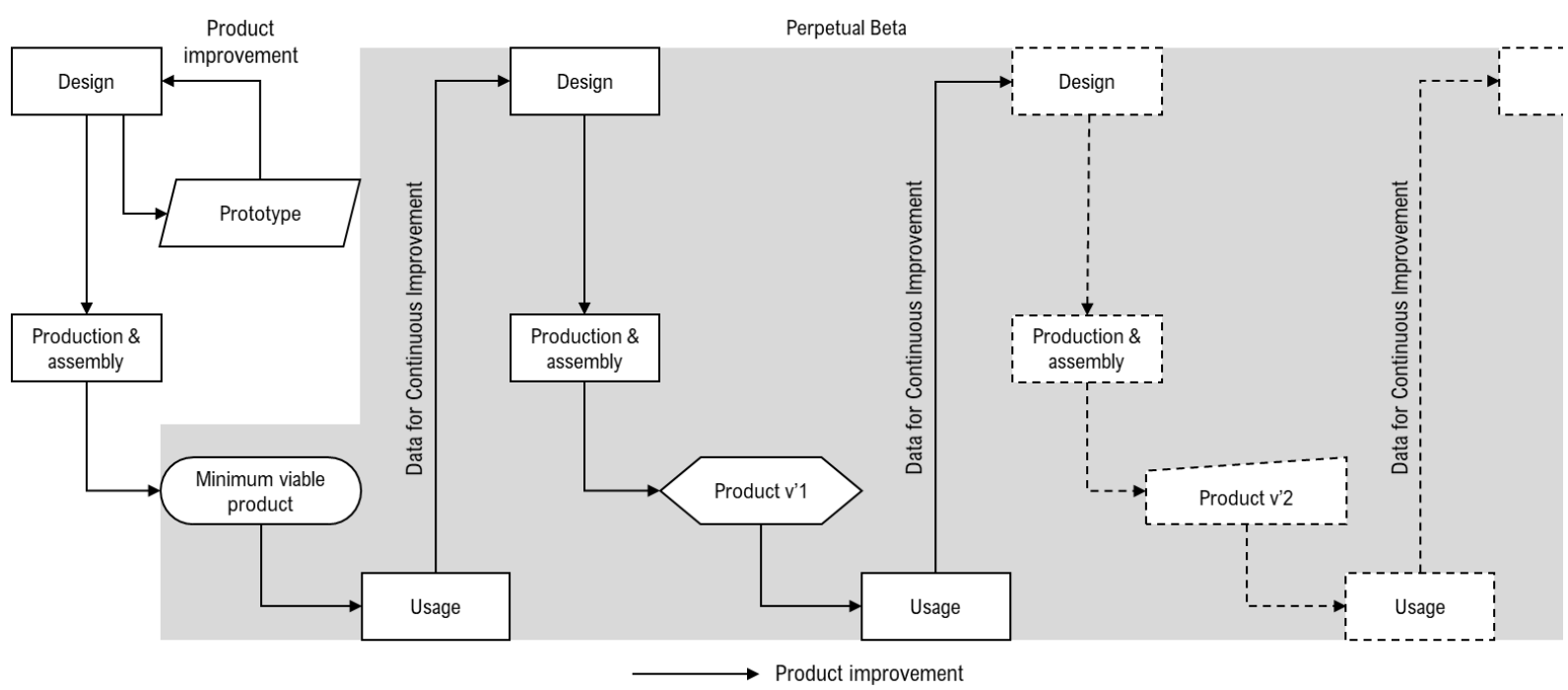

Figure 3. Stepwise development of AM-enabled design. Adapted from (Pahl et al., 2007)

\subsection{Perpetual beta}

Since the design can be updated or modified at any stage of the product life cycle, the concept of perpetual beta (O'Reilly, 2005) can now be applied to the design of tangible (physical) products. Following this concept, there is never a final design and the design remains under continual development and improvement as long as it exists. In software development, this is an established practice. As Constantinides and Fountain (2008) state "there is no question of upgrading cycles or software releases but rather a continuous, real-time product development, based on actual user feedback and usability controls". In the same way, in AM-enabled product design, the accepted concepts of version and of new product disappear. Every iteration of the product is itself a new, updated and potentially personalised version of the design (Figure 3). In this context, prototyping blends into production since firstly there is little physical distinction between prototypes and end-use products; they have the same design, material and manufacturing process (Pradel, 2012), and secondly because each product is effectively a prototype to acquire information for the next design iteration.

\subsection{Data driven design}

Continuous, real-time and incremental product development can become possible also with the integration of the Internet of Things (IoT) and Product Appropriation (Barrett, 2018; Rodriguez and Liliana, 2017). Quantitative data from the product and qualitative feedback from users can provide continuous insights on how the product is used and experienced by the consumers. This can continuously inform the design process (Constantinides and Fountain, 2008; Kurch-Lucas, 2018). 


\subsection{Populations of products}

In traditional product design, since products are iterations of the same identical design, data can be easily compared and aggregated to obtain insights for future designs. In AM-enabled design, since products are, or at least might be all different, data comparison and aggregation are more challenging. A solution could be to treat products as populations and adopt appropriate statistical methods and tools. In this extent, Artificial Intelligence (AI) could be a valuable tool to provide insights for large sets of diverse products.

\subsection{Minimum viable product}

As shown in the picture above (Figure 3), a critical element of the process will be the first product released in the market. The concept of Minimum Viable Product (MVP) aims at focusing the design effort on the core functionality (Hatch, 2016) of the product in order to reduce resources for product development (Moogk, 2012). This allows designers to rapidly reach a market-ready product that can be used to acquire actual user data (feedback). In this context, the true value of a product after its initial launch is not the volume of sales, but the data it generates (Kurch-Lucas, 2018). An example of this approach is the pop-up shop 'Knit for you' designed and run by Adidas in Berlin until March 2017 (Murray-Nag, 2017; Adidas, 2017). The aim of the shop was to explore localised production and interactive technology to co-create bespoke garments. The philosophy behind it was explicitly that of the perpetual beta. The shop was, in fact, an MVP intended to "...better understand, and improve upon, the processes that will shape our future." (Adidas, 2017).

\subsection{Agile product design process}

Several software development paradigms and models such as Waterfall (Bell and Thayer, 1976), V model (Forsberg and Mooz, 1991), Spiral (Boehm and B, 1986), Prototyping (Todd Grimm, 1998), Incremental (Pressman, 2010), etc. have been proposed over the years (Ralph, 2018). With the advent of AM technologies, product design processes and practice could be informed by such paradigms and models. For instance, some of the principles behind the Agile manifesto (Beck et al., 2001) could be adapted and/or explored in product design and development (Autodesk, n.d.).

\subsection{Meta-product}

Although connectivity is an important aspect for providing insights for future design iterations, in AM-enabled design a Meta-Product (MP) does not mean connected products as proposed by Córdoba Rubino et al. (2011). Rather MPs are designs that are not fully specified at the design stage thus they do not represent a specific product but rather an abstract 'parent', master or sample size (Bye et al., 2008) from which a potentially infinite number of tangible different products can be derived. Therefore, a MP has the flexibility to adapt and accommodate individual user requirements (for example size or fit). This idea is similar to the concept of 'Underdesign' described in Fischer and Giaccardi (2006) and the concept of deliberately unfinished designs proposed by Sinclair (2012). Meta designing does not entail less work, and fewer demands for designers but rather specifying the design variables that will be available along with their domain of variability (e.g. variable $=$ colour, domain $=$ red, green and blue). By doing this, meta-designers delineate a product solution space (Franke et al., 2009; Vesanen, 2007) that is available for designers themselves but also for others (e.g. consumers and shop assistants) to define and thus create the individual product (Paterson et al., 2014). In this context, shape grammars have provided a useful conceptual tool for defining MPs (Knight and Stiny, 2001).

\subsection{Meta-design}

Another aspect is designing the design process i.e. the design of platforms that enable non-designers (e.g. customers, shop assistants, etc.) to design products (Yavari et al., 2016; Kudus, Campbell and Bibb, 2016; Kudus, Campbell, Bibb et al., 2016; Paterson et al., 2014; Sinclair and Campbell, 2014; Sinclair, 2017). In 2006, Fischer and Giaccardi (2006) defined 'Meta-Design' (MD) as "defining and creating social and technical infrastructures in which new forms of collaborative design can take place". Similarly, Ardito et al. (2009) defined MD as the act of designing the design environment. An example of this concept is the work of Paterson (2013) where a semi-automated computer-aided design approach for personalised orthoses was developed that enabled hand therapists (non-designers) 
to rapidly and easily produce custom-fitting 3D printed wrist splints. More recently, customer oriented design platforms have been launched for different product categories such as bathroom sinks (Sandhelden, 2018) razors (Lucy Handley, 2018; Gillette, 2018) and ceiling lamps (Nichetto, 2018).

One of the obvious potential barriers to the adoptions of a continually iterated product design process is validation. There are aspects other than the need to create and invest in tooling that necessitate a design freeze. Typically, these aspects involve some form of validation of the design to ensure that the product meets safety or regulatory standards. This poses a challenge for an ever-changing design. In these circumstances, it is possible to ensure that the meta-design embodies all the requirements and that can be tested and validated. The design iterations that are then permitted are limited to any that cannot detrimentally affect the performance of the product.

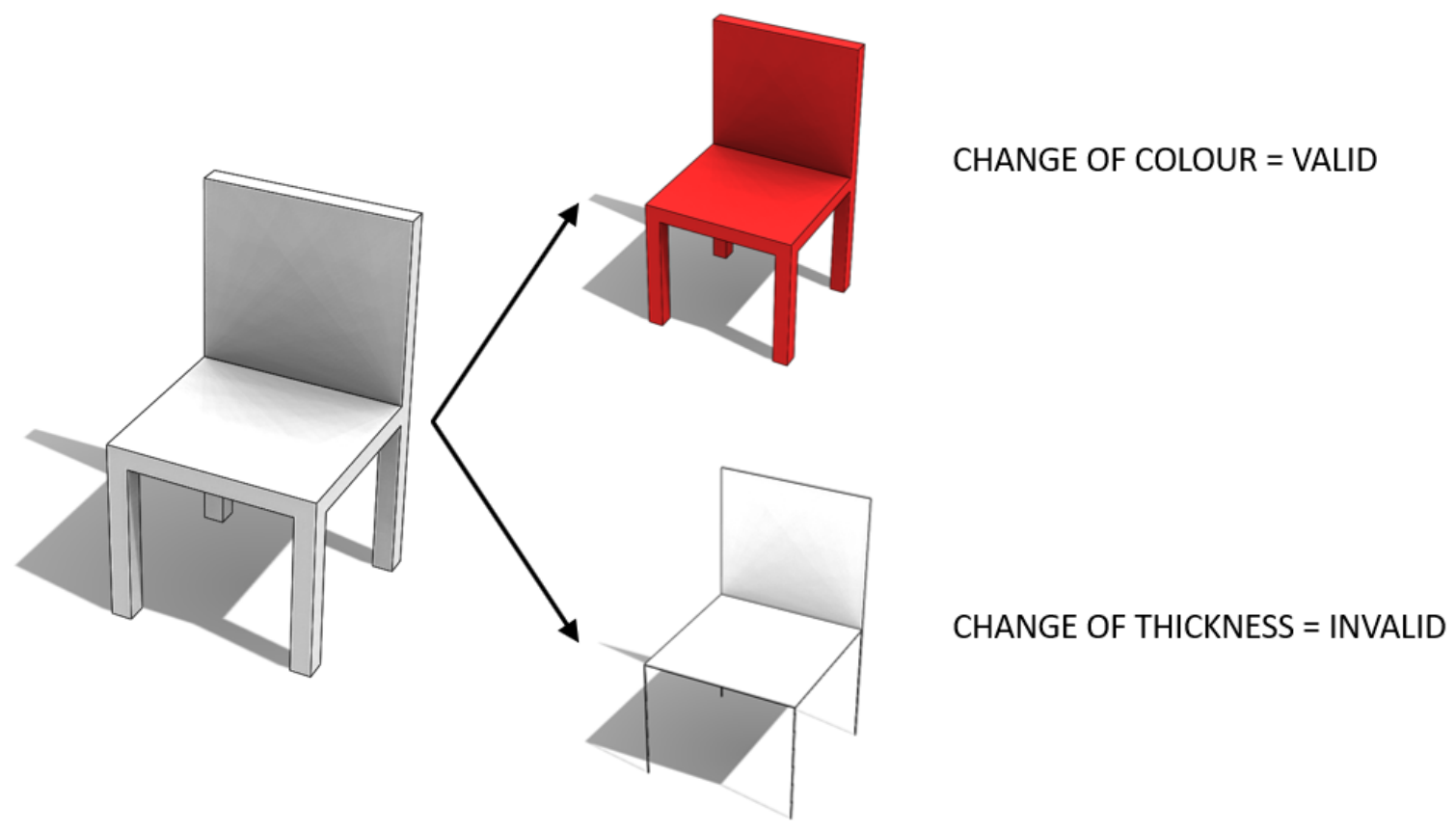

Figure 4. Example of acceptable and unacceptable developments

To take the simplest example a chair meta-design that enables the free choice of colour or surface finish would be acceptable whereas a choice of thickness that might invalidate the structural rigidity required would be rejected.

Table 1. Summary of traditional versus AM-enabled product design

\begin{tabular}{ll}
\hline Traditional product design & Digitally enabled product design \\
\hline Iconic design & Meta-product \\
Star designer & Meta-designer \\
Defined solution & Open solution \\
Rigid & Transformative \\
Top-down & Bottom-up \\
Concentrated & Distributed \\
Anticipating & Adapting \\
Ideal & Realistic \\
Universal & Contextual \\
Fixed & Evolving \\
Passive & Active \\
Spectator & Co-creator
\end{tabular}

\section{HYPOTHETICAL SCENARIO}

To illustrate our viewpoint, in this section we present a hypothetical case of a fridge, but could equally have been an iron, kettle, electric drill or other everyday household consumer product. 


\subsection{Fridge}

Let us imagine that a manufacturer of domestic appliances launches a new fridge. By following a standard design process (e.g. Ulrich \& Eppinger, 2012), the marketing team identifies the customer needs for the fridge. The design team translates those needs into design variables and defines a range of values for each variable that may satisfy the users' needs, i.e. a product design specification (PDS). Currently, if the marketing team identifies young urban couples as a good target market, the fact that these couples may live in very small apartments, means the fridge might be smaller and with a correspondingly low capacity. However, since the AM-enabled design can be fluid, there is no need (or almost no need) to focus the design on a specific target market. The marketing team might also identify the need for a specific appearance based on the style of house. However, once again, since the AM-enabled design is fluid, a specific type of fridge will be just one amongst many in a range of possible fridges. There could be a different fridge for each type (e.g. modern, high-end, retro etc.) and size of kitchen.

Currently, to answer the needs of different user groups, manufacturers develop different product models to create a range of designs, often seen as a product family. However, the usual restrictions of tooling investment apply and the number of variants in the range must be limited. Whereas in AMenabled design, it is the meta-design that can be evolved to represent every member of the family of products. To take the metaphor further, current design practice requires each of the family siblings to be developed, whereas AM-enabled design only requires one "parent" design to be created, initially.

Within the range of each design variable, that is to say the "design space", the design team creates a meta-product of the fridge i.e. a model embodying all possible fridges that can possibly satisfy users' needs. This model must fit within the company brand identity and the visual language defined for the product. The meta-product also considers design constraints derived from standard components and simulation software.

With the meta-product drafted, the design team creates the first working prototype of the fridge for performing tests and design iterations to solve the major functional issues. When a version with suitable functionality is achieved i.e. an MVP, the first product is shipped to the first customer, effectively acting as a beta-tester. The customer uses the product and provides feedback about the user experience. Concurrently, sensors embedded in the fridge collect a range of quantitative data such as on-off time, power usage, the stress in the components, etc. All these data are fed back to the designers who then update and refine the meta-product into the next iteration of the fully viable solution. The new, version 2, fridge design is then sent to a variety of new customers or eventually just one. The feedback from each new customer provides additional data that is used to update the meta-product of the fridge and create the next versions of the design. The designers can choose to respond to the feedback and change the design at any time entirely of their choosing.

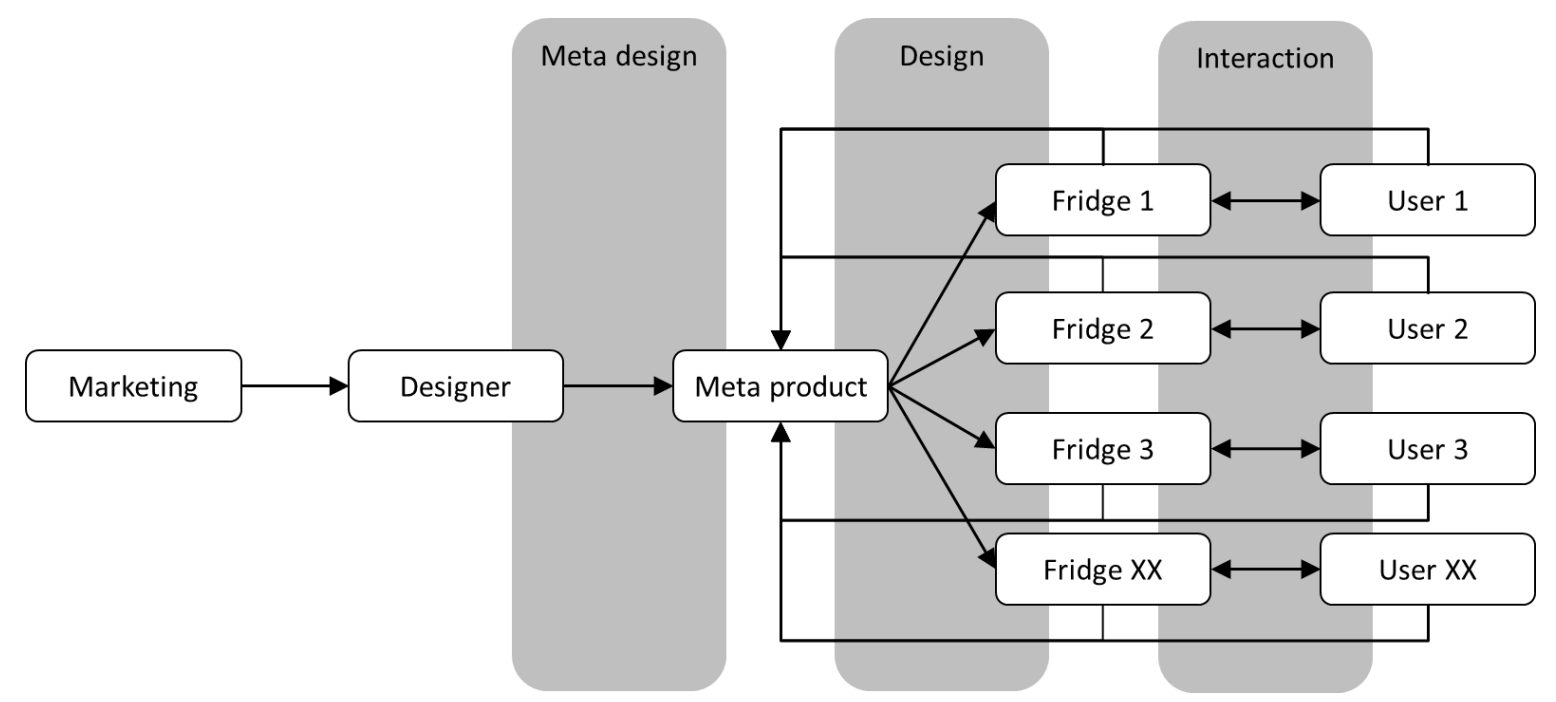

Figure 5. AM-enabled design process model

In the case of faults and poor performance after purchase, the company sends new updated components to the user to fix the relevant issues. The customer can also provide new requirements 
(such as indications for a specific compartment that fits their personal requirements and food habits). Aftermarket software can help the user identify areas of improvement, for instance, it can scan the stored food for developing personalised high-performing accessories or identify anthropometric data for enhanced ergonomics. Since the design is fluid, new personalised components of the fridge can be printed and sent to the user at any time. If the user moves to a bigger house, the fridge can be upgraded to larger capacity. If the customer changes foods habits, a newly dedicated compartments that works perfectly for the type of food can be produced and delivered. The customer, as well as the company, can upgrade, modify or repair the fridge at any given time of their choosing.

Moreover, with an increasing number of users and experiences, the data increases (eventually to "big data") the meta-product can become ever more accurate and even predict design changes that the user may want to satisfy specific needs or contexts.

\section{QUESTIONS AND ISSUES FOR FURTHER RESEARCH}

In philosophy, the concept of "liquid modernity" has been introduced to describe the fluid and mutable ethics and norms of contemporary society (Bauman, 2000). Also design and products may become "liquid" in the future. In traditional product design, the aim is to create everlasting icons that surpass untainted the mutable changes of trends and fashions. However, if the design is not fixed, but always changes it then becomes something that is liquid. As in our society, there is not such a thing as optimal or perfect. Each design is situated in a specific context at a particular time. A physical snapshot of a fluid and continuous design process.

However, for this scenario to become real there are questions and challenges to address related to the economic model, the management of updates and upgrades, the validation and certification of the product and the marketing strategy.

Is it cost effective to continually evolve the design? In software development, several development models have evolved in recent years to address this question. For instance, several software applications secure part of their revenue stream from an online version of the traditional newspaperlike subscription (e.g. Adobe). The company provides a service rather than a product. Some companies offer their services for free, subsidising their operations by advertising revenue or sponsoring (e.g. Google). Other companies provide a basic service for free and charge a fee for the premium version, which adds more advanced functionalities (e.g. Skype). In 2009, Anderson (2009) proposed the concept of 'long tail' to describe a likely economic model for the digital age. The author argues that in contrast to traditional mass manufacture where revenues are made by selling large quantities of the same identical product, the digital revolution makes it profitable to sell many unique or low volume items.

Why should it be better to evolve the design only for small improvements? Fixing the design, at least periodically, makes sense for a variety of reasons; for example, marketing, fashion, demand management, capacity, validation, quality control, etc. Even in software development, applications updates are typically fixed in numbered "releases" or versions. For instance, for products that require certifications and must satisfy standards and/or quality requirements, validation and testing take substantial time and resources within the product development process. Having to test and validate an infinite number of slightly different unique products would almost certainly prove, not only to be too time demanding but also uneconomical.

How can a brand identity be built in and controlled if the design is always changing? If the design is unfinished and can take different design languages and styles how would companies differentiate themselves and convey branding messages through form and colour? An ever-changing design poses several challenges to the branding and marketing strategy. Cultivating a certain image in consumers' minds may prove to be challenging if there is not a defined design language that conveys the brand values (Sinclair, 2012b).

In this paper, we have delineated some principles and models and that might inform product design practice in the future. Far from being prescriptive, we hope this paper initiates wider discussion about the future evolution of product design practice and research in response to technological possibilities. Just because we can do something does not mean that we should.

The authors intend to explore possible new models of the design processes and investigate the implications for design practice, design process and manufacturing. 


\section{REFERENCES}

Adidas. (2017), “Adidas Knit for you”, Available at: http://adidasknitforyou.com/ [Accessed November 27, 2018].

Anderson, C. (2009), The Longer Long Tail : How Endless Choice is Creating Unlimited Demand, Random House Business.

Ardito, C., Lanzilotti, R., ... P.M.-P. of and 2009, U. (2009), "Redefining the roles of users and designers in interactive system lifecycle", In Proceedings of CHItaly.

Autodesk. "An Agile Approach to Product Development | Autodesk", Available at: https://www.autodesk.com/industry/manufacturing/resources/mechanical-engineer/agile-productdevelopment [Accessed March 21, 2019].

Barrett, A.K. (2018), "Technological appropriations as workarounds", Information Technology \& People, Vol. 31 No. 2, pp. 368-387.

Bauman, Z. (2000), Liquid Modernity, Polity Press.

Beck, K., Beedle, M., Bennekum, A., Cockburn, A., Cunningham, W., Fowler, M. and Grenning, J. et al. (2001), "Manifesto for Agile Software Development", The Agile Alliance, Vol. 2009 No. December 14, p. 2006.

Bell, T.E. and Thayer, T.A. (1976), “Software Requirements: Are They Really a Problem?” In Proceedings of the 2nd international conference on Software engineering. IEEE Computer Society Press. pp. 61-68.

Boehm, B. and B. (1986), "A spiral model of software development and enhancement", ACM SIGSOFT Software Engineering Notes, Vol. 11 No. 4, pp. 22-42.

Bye, E., LaBat, K., McKinney, E. and Kim, D. (2008), “Optimized pattern grading”, International Journal of Clothing Science and Technology, Vol. 20 No. 2, pp.79-92.

Campbell, R.I., De Beer, D.J. and Booysen, G. (2007), "Rapid tooling strategies for product customisation and design evolution", Journal for New Generation Sciences, Vol. 5 No. 2, pp. 1-12.

Constantinides, E. and Fountain, S.J. (2008), "Web 2.0: Conceptual foundations and marketing issues", Journal of Direct, Data and Digital Marketing Practice, Vol. 9 No. 3 pp. 231-244.

Córdoba Rubino, S., Hazenberg, W. and Huisman, M. (2011), Meta Products : Meaningful Design for our Connected World. BIS Publishers.

Dieter, G. and Schmidt, L. (2012), Engineering Design. New York, McGraw-Hill Education.

Eastman, R.M. (1980), "Engineering information release prior to final design freeze", IEEE Transactions on Engineering Management, EM-Vol. 27 No. 2, pp. 37-42.

Fischer, G. and Giaccardi, E. (2006), "Meta-design: a framework for the future of end-user development", End User Development: pp. 427-457.

Forsberg, K. and Mooz, H. (1991), "The relationship of system engineering to the project cycle", INCOSE International Symposium, Vol. 1 No. 1 pp. 57-65.

Franke, N., Keinz, P. and Steger, C.J. (2009), "Testing the value of customization: when do customers really prefer products tailored to their preferences?", Journal of Marketing, Vol. 73 No. 5, pp. 103-121.

Gillette. (2018), "Razor Maker”, Available at: https://razor-maker.com/ [Accessed November 27, 2018].

Hatch, P. (2016), "The Macintosh Moment - How UX and Design Thinking help you find it - Bosch ConnectedWorld Blog", Bosh ConnectedWorld Blog. Available at: https://blog.boschsi.com/internetofthings/macintosh-moment-ux-design-thinking-help-find/ [Accessed December 5, 2018].

Heskett, J. (2003), Industrial Design, Thames \& Hudson, London.

Knight, T. and Stiny, G. (2001), "Classical and non-classical computation”, Information Technology, Vol. 5 No. 4.

Kudus, S.I.A., Campbell, R.I. and Bibb, R.J. (2016a), "Customer perceived value for self-designed personalised products made using additive manufacturing", International Journal of Industrial Engineering and Management (IJIEM), Vol. 7 No. 4, pp. 183-193.

Kudus, S.I.A., Campbell, R.I., Bibb, R.J., Abdul Kudus, S.I., Campbell, R.I. and Bibb, R.J. (2016b), “Assessing the value of 3D printed personalised products", In 7th International Conference on Mass Customization and Personalization in Central Europe (MCP-CE 2016). Novi Sad, pp. 1-10.

Kumke, M., Watschke, H., Hartogh, P., Bavendiek, A.-K. and Vietor, T. (2018), "Methods and tools for identifying and leveraging additive manufacturing design potentials", International Journal on Interactive Design and Manufacturing (IJIDeM), Vol. 12 No. 2, pp. 481-493.

Kurch-Lucas, E. (2018), "Industrial design in the age of IoT - Bosch ConnectedWorld Blog", Bosh ConnectedWorld Blog. Available at: https://blog.bosch-si.com/internetofthings/industrial-design-in-theage-of-iot/ [Accessed December 5, 2018].

Lucy Handley. (2018), "Procter \& Gamble is testing 3D printed Gillette razors", $C N B C$. Available at: https://www.cnbc.com/2018/10/18/procter--gamble-is-testing-3d-printed-gillette-razors.html [Accessed November 27, 2018].

Moogk, D.R. (2012), "Minimum viable product and the importance of experimentation in technology startups", Technology Innovation Management Review, (March), pp. 23-26. 
Murray-Nag, B. (2017), "adidas pop-up store knits bespoke garments based on a scan of your body", Designboom. Available at: https://www.designboom.com/technology/adidas-knit-for-you-03-22-2017/ [Accessed November 27, 2018].

Nichetto, L. (2018), “Alphabeta Pendant Lamp Configurator - Hem”, Available at: https://www.hem.com/products/alphabeta-configurator [Accessed December 3, 2018].

O'Reilly, T. (2005), "What Is Web 2.0 - O'Reilly Media”, Available at: https://www.oreilly.com/pub/a/web2/archive/what-is-web-20.html [Accessed December 4, 2018].

Pahl, G., Beitz, W., Feldhusen, J. and Grote, K.-H.H. (2007), Engineering Design. 3rd ed., Springer, London.

Paterson, A. (2013), Digitisation of the Splinting Process: Exploration and Evaluation of a Computer Aided Design Approach to Support Additive Manufacture, Loughborough University.

Paterson, A.M., Donnison, E., Bibb, R.J. and Ian Campbell, R. (2014), "Computer-aided design to support fabrication of wrist splints using 3D printing: A feasibility study", Hand Therapy, Vol. 19 No. 4, pp. 102113.

Pradel, P., Zhu, Z., Bibb, R.J. and Moultrie, J. (2018), "Investigation of design for additive manufacturing in professional design practice", Journal of Engineering Design.

Pressman, R.S. (2010), Software Engineering : A Practitioner's Approach, McGraw-Hill Higher Education, Boston.

Ralph, P. (2018), “The two paradigms of software development research”, Science of Computer Programming, Vol. 156, pp. 68-89.

Rodriguez, L. and Liliana. (2017), “Technology Appropriation Awareness and Identification”.

Römer, A., Pache, M., Weißhahn, G., Lindemann, U. and Hacker, W. (2001), "Effort-saving product representations in design - results of a questionnaire survey", Design Studies, Vol. 22 No. 6, pp. 473-491.

Sandhelden. (2018), “Sandhelden | Individuelle Waschbecken”, Available at: http://www.sandhelden.de/ [Accessed November 27, 2018].

Sinclair, M. (2012a), The Specification of a Consumer Design Toolkit to Support Personalised Production Via Additive Manufacturing. Loughborough University.

Sinclair, M. (2012b), The Specification of a Consumer Design Toolkit to Support Personalised Production Via Additive Manufacturing. (C) Matthew Sinclair.

Sinclair, M. (2017), "What will designers do when everyone can be a designer?” In Design for Personalisation. p. 91.

Sinclair, M. and Campbell, I. (2014), “A Classification of Consumer Involvement in New Product Development”, Proceedings of DRS 2014: Design's Big Debates.: pp. 1582-1598.

Thompson, M.K., Moroni, G., Vaneker, T., Fadel, G., Campbell, R.I., Gibson, I. and Bernard, A. et al. (2016), "Design for additive manufacturing: trends, opportunities, considerations, and constraints", CIRP Annals Manufacturing Technology, Vol. 65 No. 2 pp. 737-760.

Grimm, T. (1998), “The human condition: a justification for rapid prototyping”, Time-Compression Technologies, Vol. 3 No. 3.

Ulrich, K.T. and Eppinger, S.D. (2012), Product Design and Development. 2nd ed. Milano, McGraw-Hill.

Vesanen, J. (2007), "What is personalization? A conceptual framework", European Journal of Marketing, Vol. 41 No. 5/6, pp. 409-418.

Yavari, H., Kudus, S.I.A. and Campbell, R.I. (2016), "User involvement in design: a case study of using an AMenabled mass customisation and personalisation (MC\&P) toolkit", In Proceedings of 2015 14th Rapid Design, Prototyping and Manufacture conference (RDPM 14). pp. 15-16. 
